\title{
ENSINO E
}

\section{APRENDIZAGEM}

ONLINE NO

ZIMBABWE:

\author{
ALGUMAS \\ OPINIÕES \\ E CRENÇAS
}

ENSEÑANZA Y APRENDIZAJE ONLINE EN ZIMBABWE: ALGUNAS OPINIONES E CRENÇAS

ONLINE TEACHING AND LEARNING IN ZIMBABWE: SOME OPINIONS AND BELIEVES

Diocleciano Nhatuve*

Universidade do Zimbabwe | Universidade Eduardo Mondlane

Moisés Mafuiane**

Seminário Bíblico e Teológico de Maputo

RESUMO: Neste artigo discutimos as opiniões, percepções e sugestões de um grupo de estudantes universitários zimbabweanos e seus pais/encarregados sobre o ensino-aprendizagem online, com o objetivo geral de entender até que ponto as suas mundividências (des)favorecem esta modalidade de ensino. O estudo ancora-se nos princípios teóricos da aprendizagem online e numa metodologia mista. Os resultados revelam a superioridade percentual das percepções e sugestões adversas aos princípios e ao processo de ensinoaprendizagem online. No entanto, embora pouco representativos, registram-se igualmente ideias e sugestões favoráveis que não devem ser ignoradas. Neste sentido, argumentamos a favor da mudança de atitude negativa e da adaptação às novas formas de aprendizagem. As instituições de ensino, ao conceberem e implementarem projetos de ensino-aprendizagem online, devem incluir atividades de consciencialização do tecido social sobre a relevância desta modalidade de educação.

PALAVRAS CHAVE: Ensino-aprendizagem online. Estudantes universitários e seus pais. Opiniões, percepções e sugestões. Impacto. Mudança de atitude.

RESUMEN: En este artículo discutimos las opiniones, percepciones y sugerencias de un grupo de estudiantes universitarios de Zimbabue y sus parientes sobre la enseñanza y el aprendizaje online, con el objetivo general de comprender en qué medida sus cosmovisiones (des)favorecen esta modalidad de enseñanza. El estudio se basa en los principios teóricos del aprendizaje online y en

\footnotetext{
* 1 Doutor em Linguística do Português pela Universidade de Coimbra. Leitor de Língua portuguesa na Universidade doZimbabwe. E-mail: djrnhatuve@gmail.com

** Mestre em Linguística pela Universidade Eduardo Mondlane. Docente no Seminário Bíblico e Teológico de Maputo. E-mail: mlmafuane@gmail.com
} 
una metodología mixta. Los resultados revelan el porcentaje superior de percepciones y sugerencias adversas a los principios y al proceso de enseñanza-aprendizaje online. Sin embargo, a pesar de los pocos representantes, también hay ideas y sugerencias favorables que no deben ser ignoradas. En este sentido, defendemos el cambio de actitudes negativas y la adaptación a nuevas formas de aprendizaje. Las instituciones educativas, al diseñar e implementar proyectos de enseñanza-aprendizaje online, deben incluir actividades de sensibilización de la sociedad sobre la relevancia de este tipo de educación.

PALABRAS CLAVE: Enseñanza-aprendizaje online. Estudiantes universitarios y sus parientes. Opiniones, percepciones y sugerencias. Impacto. Cambio de actitud.

ABSTRACT: The aim of this paper is to understand how and to what extent students' and parents' worldview about online teaching and learning affects this modality of education. In this regard, we discuss opinions, perceptions and suggestions of Zimbabwean university students and their parents. The study is based on the principles of online learning theories and on qualitative and quantitative approaches. Results reveal that opinions, perceptions and suggestions unconducive to online learning expressively surpass the percentage of those in line with the principles and process of online education. However, although conducive perceptions and suggestions are less than the late ones, they must never be neglected. We argue that students and society in large need to change negative attitude towards online learning and accept the new ways of learning. Therefore, educational institutions must include in their projects of online teaching and learning activities aiming to raise awareness of the society in what regards the relevance of online learning.

KEYWORDS: Online teaching and learning. University students and their parents. Opinions, perceptions and suggestion. Impact. Change of attitude.

\section{INTRODUÇÃO}

O desenvolvimento da ciência e da tecnologia impõe profundas mudanças nos sistemas de ensino quer em países desenvolvidos, quer em países em desenvolvimento. É que a adesão às tecnologias digitais é cada vez mais crescente quer num, quer noutro contexto e os benefícios do uso dessas tecnologias para o ensino-aprendizagem são largamente difundidos em diferentes contextos. Aliás, o desenvolvimento de competências de uso das tecnologias de informação e comunicação (TIC) é, hoje em dia, uma das grandes prioridades dos sistemas de ensino, na formação do Homem para responder às exigências do irreversível fenómeno de globalização. As mudanças que se impõem envolvem vários setores e entidades que viabilizam o processo de formação do Homem. Há necessidade de mudança de comportamentos, de estratégias, de materiais e de ambientes (MOREIRA; SCHLEMMER, 2020; AMANTE; OLIVEIRA, 2019; MENDES et al. 2018; MOREIRA; RIGO, 2018; BATES, 2017). Sendo verdade que estas mudanças ocorrem em sistemas de ensino diferentes (por um lado, em contextos social, material e economicamente preparados para tais mudanças e, por outro, em sistemas de ensino socioeconomicamente menos preparados), é óbvio que ocorram de forma heterogênea. Há certos aspectos cuja mudança é mais rápida e fácil (uso das TIC) e outros cuja a mudança, devido a várias circunstâncias, é mais lenta e difícil. De uma forma geral, nos países desenvolvidos, as mudanças têm lugar sem sobressaltos, enquanto nos sistemas de países em desenvolvimento, registram-se dificuldades acentuadas.

Neste contexto, intentamos com este trabalho avaliar até que ponto as opiniões e crenças de estudantes e pais/encarregados sobre o processo de ensino-aprendizagem online (des)favorecem o sucesso no uso desta modalidade de educação em países em desenvolvimento. Mais especificamente, considerando que, com a eclosão da pandemia da Covid-19, as instituições de ensino superior zimbabweanas, à semelhança do que aconteceu em outros países da região e do mundo, adotaram a modalidade de ensinoaprendizagem online, pretendemos identificar e discutir as principais opiniões, crenças e sugestões de estudantes universitários e respetivos pais que, de forma abrupta, se viram obrigados a recorrer ao ensino-aprendizagem online (no Zimbabwe).

O interesse por este tema fundamenta-se, em primeiro lugar, pelo fato de o ensino-aprendizagem online, devido aos seus benefícios e à dinâmica social, ter-se revelado uma modalidade incontornável para um ensino que, realmente, sirva aos interesses das respetivas sociedades. Em segundo plano, a escolha deste tema justifica-se pelo fato de o nosso grupo alvo (estudantes e pais inquiridos), após cerca de um semestre de ensino-aprendizagem online (processo de ensino-aprendizagem e respetiva avaliação), revelar o fracasso e

\begin{tabular}{l|l} 
Nhatuve \& Mafuiane & Ensino e aprendizagem online no Zimbabwe: algumas opinióes e crenças
\end{tabular} 
a inviabilidade do processo e, ao mesmo tempo, revelar comportamentos e atitudes incompatíveis com os mecanismos de educação com recurso a ferramentas digitais online (NHATUVE, 2020).

Entretanto, o estudo releva do fato de representar um contributo valioso na área de ensino- aprendizagem online no contexto específico de estudantes universitários zimbabweanos, bem como de todos os sistemas de ensino da região que, como é sabido, partilham condições socioeconómicas e culturais similares. Aliás, no estudo, identificamos as principais opiniões, crenças e sugestões de pais e estudantes que partilham o mesmo espaço sociofamiliar onde o estudante deve realizar as diferentes atividades de aprendizagem online e apresentamos argumentos favoráveis para a consciencialização sobre a pertinência, possibilidade e viabilidade do ensino-aprendizagem online, não só para fazer face às dificuldades impostas pela pandemia da Covid-19, mas também como forma de acolher de maneira positiva as mudanças impostas pelos avanços da ciência e da tecnologia na área da educação.

A base empírica deste estudo é constituída por opiniões e sugestões de estudantes universitários zimbabweanos de diferentes cursos e dos respectivos pais sobre a viabilidade da aprendizagem online. Estes dados foram recolhidos no âmbito de um inquérito sobre o ensino-aprendizagem online que, embora seja largamente difundido e as respetivas vantagens reconhecidas (ALLY, 2008, p. 17-18) graças ao uso e difusão das TICs, representou, para o grupo alvo (nossos inquiridos) uma prática nova para a qual precisava de se adaptar.

O estudo é norteado pelos princípios de ensino e de aprendizagem online como subparte da teoria de ensino e de aprendizagem em geral (ANDERSON, 2008a, p. 46-47). No conjunto destes princípios encontram-se aportes sociopedagógicos e didáticos (BATES, 2017, p. 109-144) que nos permitem não só analisar de forma crítica as opiniões, sugestões e crenças sobre o ensino-aprendizagem online, como também avançar estratégias e comportamentos favoráveis a uma aprendizagem online motivadora e de qualidade.

\section{CONSPECTO TEÓRICO}

A atual dinâmica social, marcada pelo inconfundível e irreversível avanço da ciência e da tecnologia e, no decurso do ano de 2020 , pela pandemia da covid-19, propicia o uso, cada vez mais crescente, da modalidade online de ensino-aprendizagem, com o intuito de formar cidadãos competentes e socialmente úteis (ALLY, 2008). Na verdade, a maior adesão ao ensino-aprendizagem com recurso a meios digitais online justifica-se pelo fato de a maior parte de instituições de ensino bem como a sociedade em geral reconhecerem os múltiplos benefícios associados a um ensino-aprendizagem online cuidadosa e eficazmente desenhado e implementado.

De acordo com Ally (2008, p. 17-18), o ensino-aprendizagem online tem benefícios para os professores e alunos na medida em que se caracteriza pela flexibilidade no que tange ao tempo e ao espaço de aprendizagem, isto é, o processo de aprendizagem online não conhece barreiras de tempo ou de espaço. Os materiais de aprendizagem online permitem uma aprendizagem assíncrona relevante, recorrendo a livros, artigos, vídeos atuais diversificados e de alta qualidade, por um lado, enquanto as sessões síncronas, recorrendo a várias ferramentas e plataformas de ensino-aprendizagem online (google classroom, google meet, zoom, youtube, entre outros), facilitam e enriquecem a comunicação entre os alunos e os professores. Os professores podem, facilmente, orientar o aluno para o desenvolvimento de competências relevantes que tenham um impacto positivo na sociedade, recomendando-lhe informações e materiais adequados.

Entretanto, "[...] o que sabemos é que uma aprendizagem online eficaz resulta de um design e planeamento instrucionais cuidadosos, usando um modelo sistemático de design e desenvolvimento" (MATTAR; LOUREIRO; RODRIGUES, 2020, p. 2). A modalidade, a estratégia, a relação aluno-professor, os papéis do professor e do aluno, a sincronia da comunicação, as avaliações e fontes de feedback são de vital importância (MEANS, BAKIA; MURPHY, 2014).

Subscrevendo as ideias dos autores arrolados no parágrafo anterior, é preciso sublinhar que o design e o planeamento de uma aprendizagem online, tal como acontece com o ensino-aprendizagem em geral, não se deve limitar na definição e concepção de 
conteúdos e apetrechamento de infraestruturas escolares. Tratando-se de um modelo de educação relativamente novo, que algumas sociedades ainda não estão moral e culturalmente preparadas para o acolher, há uma urgência, sobretudo em contextos em que a aprendizagem online é uma prática nova, de o design, o planeamento e a implementação do ensino-aprendizagem incluírem a consciencialização da instituição sociofamiliar sobre o seu papel, para que o processo traga os benefícios desejados.

Na tentativa de apresentar uma teoria sobre a aprendizagem online, Anderson (2008a, p. 47-48) alerta para o fato de os alunos, na maioria de casos, começarem a aprendizagem online com mundividências, hábitos, percepções e preconceitos incongruentes com esta modalidade de ensino-aprendizagem. Esta situação capitaliza a necessidade de, no design do ensino-aprendizagem online, os professores e as instituições de ensino priorizarem também campanhas de sensibilizar não só os alunos, como também toda a instituição sociofamiliar, sobre a relevância, os materiais, as atitudes e os papéis de cada entidade para a fluidez da aprendizagem online no contexto familiar (ANDERSON, 2008b).

Ademais, este autor advoga que uma aprendizagem online deve ser "[...] community-centred, knowledge-centred, learner-centred, and assessment-centred" (ANDERSON, 2008a, p. 46-47). As questões que se despoletam com estes pressupostos, tendo em mente as diferenças que caracterizam as sociedades no que toca à sua prontidão sociocultural, moral e econômica para aderir ao ensinoaprendizagem online, têm que ver com os casos em que as comunidades e os alunos, devido às suas mundividências e percepções e aos seus hábitos e preconceitos, não aprovam a modalidade online de ensino e/ou enfrentam muitas dificuldades neste processo. As dificuldades relacionadas com a aprendizagem online, sobretudo no tempo da pandemia da Covide-19, são várias e são relatadas por autores de várias partes do mundo (ALI, 2020; BENTES; FERREIRA; SILVA, 2020; DEMUYAKOR, 2020; NHATUVE, 2020; SANTOS; ZABOROSKI, 2020, entre outros).

O estudo de Ali (2020), baseado em dados sobre a aprendizagem online por estudantes universitários, revela que, para além de meios compatíveis para viabilizar tal aprendizagem (computadores, smartphones, etc.), a prontidão, a capacidade, a confiança e a motivação de professores, alunos e sociedade são aspectos que afetam o uso das tecnologias de informação e comunicação para a aprendizagem online. Por seu turno, um estudo feito por Demuyakor (2020, p. 1-9) envolvendo estudantes ganeses em Universidades chinesas indica que a maioria de estudantes enfrentou dificuldades relacionadas com os altos custos da aprendizagem online e com a baixa qualidade dos serviços de Internet.

Relativamente à África subsaariana, o relatório das Nações Unidas sobre o impacto da Covid-19 revela que cerca de $90 \%$ de estudantes não têm acesso a computadores domésticos e 82\% não tem acesso à Internet (IMPACTO DA COVID-19 EM ÁFRICA, 2020, p. 1-26) e, consequentemente, enfrentam dificuldades acentuadas para levar a cabo uma aprendizagem online eficaz. Por seu turno, Nhatuve (2020, p. 207-226), estudando comportamentos, ações e condições de estudantes universitários da região austral de África, constatou que cerca de $70 \%$ dos inquiridos se queixavam do insucesso e frustração na aprendizagem online a que foram submetidos como forma de minimizar os efeitos da pandemia da Covid-19.

De acordo com este autor, preconceitos relativamente à modalidade online de ensino-aprendizagem, falta de preparação moral e material e a dificuldade de reservar tempo para se dedicar à aprendizagem online no contexto familiar são alguns dos aspectos que resultaram no fracasso do processo de ensino-aprendizagem online neste grupo alvo.

Já no contexto brasileiro, estudos de Santos e Zaboroski (2020) e de Bentes, Ferreira e Silva (2020) apontam como desafios na aprendizagem online: (1) a falta de recursos nas escolas, (2) a necessidade de preparação dos alunos, (3) a desigualdade no acesso à Internet, (4) a fragilidade psicológica, (5) o tédio, (6) a não aceitação da modalidade de ensino- aprendizagem online e (7) os problemas familiares.

Conforme se pode depreender, vária literatura sobre o ensino-aprendizagem online sublinha a pertinência desta modalidade de educação, destacando os benefícios que proporciona ao aluno, ao professor e a toda a sociedade. Contudo, os mesmos estudos, sobretudo aqueles cuja base empírica envolve dados de ensino-aprendizagem online em contextos cuja sociedade ainda não está devidamente preparada para este tipo de ensino, indicam dificuldades de diversa ordem. Para os propósitos deste estudo, das diversas dificuldades, interessa-nos focalizar aquelas que têm que ver com a mundividência, os preconceitos, os hábitos, a falta de 
preparação moral, a dificuldade de reservar tempo para se dedicar à aprendizagem online no contexto familiar, a não aceitação da modalidade de ensino-aprendizagem online e os problemas familiares, para melhor discutirmos as opiniões, as crenças e sugestões dos nossos inquiridos sobre o ensino-aprendizagem online.

\section{ESTUDO EMPÍRICO}

Nesta seção, descrevemos a estratégia que usámos para a coleta de dados e a constituição da amostra que serve como base empírica do nosso estudo. Para além desta descrição, apresentamos os procedimentos práticos a que recorremos para a análise dos dados que consiste na interpretação e discussão de dados referentes às opiniões, crenças e sugestões de estudantes e seus pais/familiares sobre o ensino-aprendizagem online.

\subsection{METODOLOGIA}

Os dados que nós analisamos neste estudo foram recolhidos através de um inquérito sobre o ensino-aprendizagem online através da plataforma Surveyplanet, cujo acesso foi/é possível através do link https://s.surveyolanet.com/oJNbQm0-q. A recolha destes dados decorreu entre 1 de julho e 31 de dezembro de 2020.

A base empírica é constituída por dados de 204 estudantes de 4 instituições de ensino superior do Zimbabwe que frequentavam diferentes cursos de graduação e pós-graduação. Estes estudantes são de ambos os sexos e tinham idades entre os 18 e 35 anos. Das informações facultadas por este grupo alvo, selecionámos aquelas que representam opiniões, crenças e sugestões sobre o ensinoaprendizagem online.

A nossa experiência de ensino online envolvendo a maioria dos nossos inqueridos, os quais se queixaram do insucesso, da frustração e da desmotivação durante o ano letivo de 2020, permitiu-nos constatar a existência de preconceitos/crenças (como: o ensino online não promove a qualidade; eu só consigo aprender quando o professor explica em sala de aula física, entre outros (NHATUVE, 2020)) associados à aprendizagem online e de uma certa negação deste tipo de educação.

Estas constatações e o fato de acreditarmos que os preconceitos, os hábitos e as crenças de estudantes e seus familiares (ANDERSON, 2008), sobretudo em contextos em que a modalidade de ensino-aprendizagem online é nova, podem ter um impacto negativo no processo de aprendizagem online, catapultaram e justificam o nosso interesse em analisarmos o tipo de informação que constitui a nossa base empírica.

A análise de dados, entretanto, consiste na apresentação, em gráficos, das principais opiniões, crenças e sugestões sobre o ensinoaprendizagem online. Para além da apresentação de dados, faz-se uma interpretação e discussão dos mesmos à luz dos pressupostos teóricos apresentados por Anderson (2008), Ally (2008), Means, Bakia e Murphy (2014), entre outros. A discussão é feita com base nos aportes de natureza teórica apresentados por estes autores e também com base nos resultados de outros estudos sobre o ensinoaprendizagem online, tais como os de Nhatuve (2020), Santos e Zaboroski (2020), Ali (2020), Bentes, Ferreira e Silva (2020).

\subsection{OPINIÕES, CRENÇAS E SUGESTÕES SOBRE O ENSINO-APRENDIZAGEM ONLINE}

Os dados sobre as opiniões, crenças e sugestões acerca do ensino-aprendizagem online estão apresentados nos gráficos 1, 2 e 3 abaixo. O primeiro gráfico, referente às opiniões e crenças dos estudantes, representa a distribuição de 279 respostas dadas por um universo de 204 inquiridos sobre este assunto (portanto, alguns dos informantes escolheram mais de uma opção das que apresentámos no respetivo questionário). No gráfico 2, por seu turno, estão representados dados estatísticos correspondentes a 194 contribuições dos pais/encarregados dos estudantes envolvidos neste estudo sobre o mesmo assunto. Finalmente, as sugestões dos nossos inquiridos estão representadas no gráfico 3. Trata-se de cerca de 50 contribuições dadas para a questão número 16 do nosso inquérito. 
Gráfico 1: Opiniões e crenças de estudantes sobre a aprendizagem online

\section{Q.14: Qual é a sua opinião sobre a aprendizagem online?}

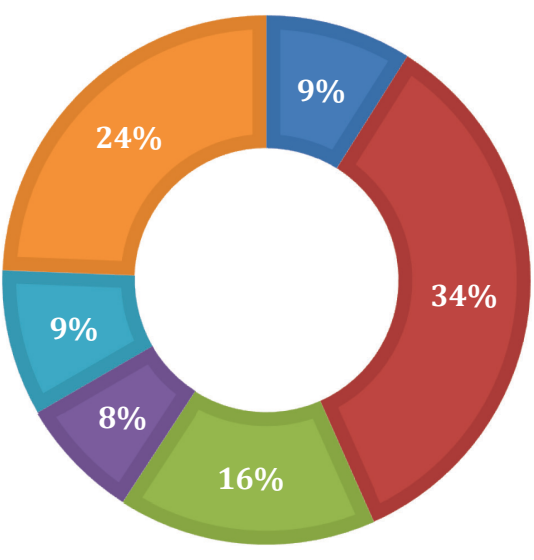

Fonte: Autores (2021)
- As instituições devem adotar o ensinoaprendizaem online

As instituições devem encorajar o ensino online e o presencial

A aprendizagem online não é recomendável pois não temos Internet nem computadores

- A aprendizagem online promove o trabalho independente do aluno

A aprendizagem online promove o plágio

A leitura do gráfico 1 acima revela duas situações óbvias sobre a questão do ensino-aprendizagem online num contexto em que o uso das TICs, apesar de vários constrangimentos, tende a beneficiar a maioria dos cidadãos, sem, no entanto, ser acompanhado pela devida consciencialização e preparação para o seu uso harmonioso, sobretudo no âmbito de ensino-aprendizagem. O gráfico demonstra que há, no seio dos nossos inquiridos, posicionamentos favoráveis ao ensino-aprendizagem online e também posicionamentos desfavoráveis a esta modalidade de ensino-aprendizagem, sendo, neste caso, relevante a análise quantitativa das opiniões e crenças que, em conformidade com a literatura arrolada no enquadramento teórico (ANDERSON, 2008; ALLY, 2008; MATTAR; LOUREIRO; RODRIGUES, 2020; MEANS, BAKIA; MURPHY, 2014, entre outros), são (des)favoráveis a um processo harmonioso de ensino-aprendizagem online.

Neste contexto, considerámos como ideias e crenças (des)favoráveis as seguintes:

\section{Ideias e crenças favoráveis:}

a. $\quad$ As instituições devem adotar o ensino-aprendizagem online (9\%);

b. As instituições devem encorajar o ensino online e o presencial (34\%);

c. A aprendizagem online promove o trabalho independente do aluno (8\%).

\section{Ideias e crenças desfavoráveis:}

a. A aprendizagem online não é recomendável pois não temos Internet nem computadores (16\%);

b. A aprendizagem online promove o plágio (9\%);

c. A aprendizagem online não promove a qualidade da educação (24\%).

Os dados estatísticos apresentados no gráfico 1 (referente às opiniões e crenças dos nossos inquiridos) indicam um total de $51 \%$ de opiniões e crenças que encorajam e promovem uma atitude positiva de diversas entidades (estudantes, professores e instituições de ensino) para a viabilização do ensino-aprendizagem online. Em contrapartida, registramos um cumulativo de $49 \%$ de posicionamentos desfavoráveis, o que representa uma diferença de $1 \%$ relativamente às posições contrárias. Esta situação, entretanto, prenuncia um certo ceticismo dos estudantes envolvidos neste estudo relativamente à eficácia da modalidade online de ensino-aprendizagem, neste momento, adotada para contornar os efeitos negativos da pandemia da Covid-19. 
Relativamente às ideias dos pais/encarregados dos nossos inquiridos, os dados do gráfico 2 abaixo revelam a existência de aspectos (des)favoráveis, alguns dos quais relevantes sob o ponto de vista socioeconómico e outros pertinentes para a criação de uma consciência coletiva sobre a necessidade de promover a aceitação desta modalidade de ensino (gráfico 2).

Gráfico 2: Opiniões e crenças dos pais/encarregados sobre o ensino-aprendizagem online

\section{Q.15: Qual é a opinião dos seus pais/encarregados sobre o ensino- aprendizagem online (por favor, pergunte!)?}

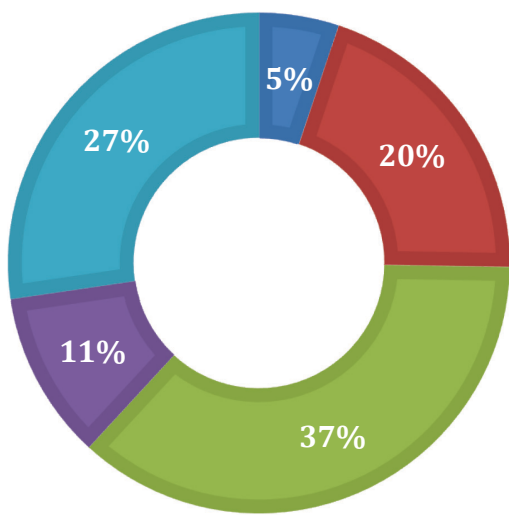

É perda de tempo

Não promove qualidade

É muito caro

É muito bom e necessário

É preciso combinar o ensino online e o presencial

Fonte: Autores (2021)

À semelhança do que registrámos no gráfico referente às opiniões e crenças dos estudantes, identificam-se, por parte dos pais e encarregados, ideias favoráveis ao processo de ensino-aprendizagem online e também ideias desfavoráveis.

\section{Ideias e crenças favoráveis:}

a. $\quad$ É muito bom e necessário (11\%);

b. É preciso combinar o ensino online e o presencial (27\%).

\section{Ideias e crenças desfavoráveis:}

a. É perda de tempo (5\%);

b. $\quad$ Não promove a qualidade da educação (20\%);

c. É muito caro (37\%).

Contrariamente ao que observámos no gráfico 1 , as ideias e/ou crenças favoráveis à modalidade online da educação totalizam valores percentuais iguais a 38\%, enquanto as que representam posicionamentos ou mundividências menos favoráveis atingem índice percentual de 62\%. Mais claramente, esta disposição indica a falta de prontidão em termos morais, económicos e sociais da instituição sociofamiliar para criar um ambiente adequado para a fluidez do processo de aprendizagem online e, consequentemente, pouco investimento moral e material para viabilizar o processo.

Finalmente, no gráfico 3 abaixo, representamos as principais sugestões de estudantes sobre o processo de ensino-aprendizagem online. Estas sugestões, na sua maioria, relevam do fato de, para além de aspectos de índole moral e socioeconómica, despoletarem a discussão sobre os papéis das instituições sociofamiliar e escolar na criação de condições para a viabilização da aprendizagem, e sobre o tempo e plataformas digitais necessários. 
Gráfico 3: Sugestões sobre o ensino-aprendizagem online

\section{Q.16: Sugestões}

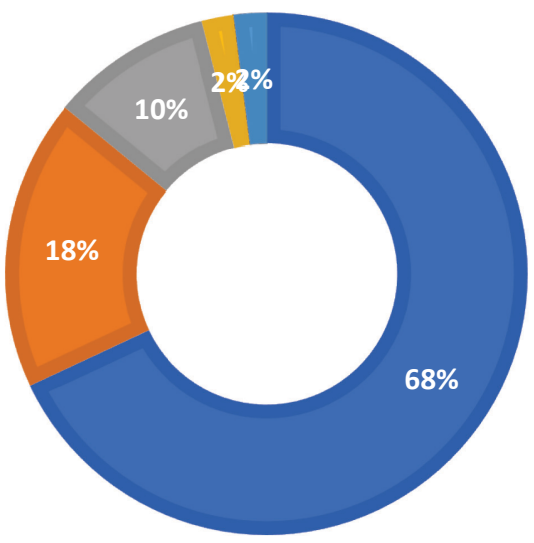

As instituições de ensino devem providenciar Internet

Deve parar-se com o ensino online

É preciso mais tempo para a realização das atividades online

É preciso consciencializar estudantes sobre o ensino aprendizagem online

É preciso usar plataformas adequadas

Fonte: Autores (2021)

À semelhança do comportamento observado nos outros dois gráficos, há, no gráfico 3, aspectos favoráveis ao uso da modalidade online de educação e outros menos favoráveis:

III.

a. É preciso mais tempo para a realização das atividades online (10\%);

b. $\quad$ É preciso consciencializar os estudantes sobre o ensino-aprendizagem online (2\%);

c. É preciso usar plataformas adequadas (2\%);

\section{Sugestões desfavoráveis:}

a. $\quad$ As instituições de ensino devem providenciar Internet (68\%);

b. Deve parar-se com o ensino-aprendizagem online (18\%).

Em correspondência à tendência geral observada nos gráficos 1 e 2, destacamos, no gráfico das sugestões dos nossos inquiridos, um índice percentual expressivamente superior de propostas desfavoráveis (com um cumulativo de 86\%) à implementação harmoniosa do ensino-aprendizagem online, em relação às sugestões favoráveis (com um total de 14\%). Os aspectos desfavoráveis dizem respeito ao papel da instituição sociofamiliar na criação de condições para que a aprendizagem online (no contexto familiar) possa ter lugar sem sobressaltos. Já as propostas favoráveis têm que ver com a necessidade de tempo, com a criação de condições morais para a aprendizagem online e com o uso de meios digitais adequados.

\subsection{DISCUSSÃO}

Indicamos como objetivo geral deste estudo avaliar até que ponto as opiniões e crenças de estudantes e pais sobre o processo de ensino-aprendizagem online (des)favorecem o sucesso no uso desta modalidade de educação em países em desenvolvimento, com particular destaque para o contexto zimbabweano. Nesta perspectiva, a análise dos dados apresentados nos gráficos 1, 2 e 3, de forma geral, revela índice elevado de opiniões, crenças e sugestões que não favorecem uma aprendizagem online harmoniosa no contexto familiar, em oposição àquelas que são favoráveis. 
É preciso realçar que considerámos como aspectos favoráveis aqueles que convergem com os principais pressupostos teóricos relativos à educação online (ANDERSON, 2008a; 2008b; ALLY, 2008; MATTAR; LOUREIRO; RODRIGUES, 2020) ou aqueles cujo teor é abonatório a estes princípios teóricos. Por seu turno, considerámos aspectos desfavoráveis aqueles que não sendo corroborativos para os preceitos apresentados por estes autores, podem pôr ou põem em causa a aprendizagem online. Portanto, sendo elevados os índices percentuais destes últimos aspectos, o nosso estudo sugere, de uma forma geral, que no seio do nosso grupo alvo (estudantes e seus pais/encarregados) prevalecem preconceitos e mundividências adversas a uma educação online harmoniosa.

No que diz respeito às ideias e crenças desfavoráveis à aprendizagem online destacamos, em primeiro lugar, a negação da modalidade do ensino-aprendizagem online (a aprendizagem online não é recomendável pois não temos Internet nem computadores (16\%); é perda de tempo (5\%); é muito caro (37\%)) por alegadamente acarretar muitos custos, sem ter nenhum benefício.

A questão da negação da modalidade online da educação representa um impacto negativo direto dos preconceitos, dos hábitos e das crenças de estudantes e seus familiares (ANDERSON, 2008a), o que impõem que no design, planeamento e/ou implementação da educação online (MATTAR; LOUREIRO; RODRIGUES, 2020, p. 2), sobretudo em sociedades em desenvolvimento, se inclua, como procedimento base, a educação social e moral sobre a modalidade online de aprendizagem. A situação da rejeição desta modalidade de ensino-aprendizagem é igualmente relatada por Santos e Zaboroski (2020), não sendo, portanto, exclusiva do contexto zimbabweano.

De acordo com Anderson (2008a, p. 46-47), a aprendizagem online é "learner-centred". Isto significa que, embora não seja independente, o estudante é o protagonista do processo de aprendizagem online, ou seja, ele é o executor das atividades e decisões chave para a sua aprendizagem. Contudo, se este estudante e pessoas próximas no contexto familiar rejeitam esta modalidade de aprendizagem, são iminentes e previsíveis o fracasso e o insucesso por falta de automotivação e da motivação vinda da instituição familiar.

Considerar que o ensino-aprendizagem online acarreta muitos custos é, obviamente, um ponto relacionado com a realidade socioeconómica que é igualmente indicada por Demuyakor (2020). No entanto, achamos justo que este assunto seja ponderado em consideração de todos os custos de um ensino presencial em que o estudante tem de se deslocar da casa onde vive com a família para viver numa residência universitária ou em casa arrendada.

Com a atual dinâmica social caracterizada pela proliferação das tecnologias digitais e, desde os finais de 2019, pela pandemia da Covid-19 que forçou o encerramento das instituições de ensino e a adoção, por muitos países, do ensino-aprendizagem online, considerar que esta forma de educação é perda de tempo ou não tem nenhum benefício é menos consensual. Embora haja trabalhos que relatam as suas inconveniências, muitas das vezes relacionadas com as dificuldades na sua implementação (ALI, 2020; DEMUYAKOR, 2020; NHATUVE, 2020), existem provas científicas e vivas que atestam as suas vantagens quer para a sociedade, quer para estudantes, quer ainda para os professores (ALLY, 2008).

Como consequência destas opiniões e crenças adversas aos mecanismos online de ensino-aprendizagem, tal como discutido nos parágrafos acima, a maioria das sugestões sobre esta modalidade de ensino é oposta aos seus princípios e menos vantajosa, tendo em conta, não só a atual situação da pandemia da Covid-19, como também as transformações por que passam as sociedades com o desenvolvimento da ciência e da tecnologia, numa altura em que a competência em TICs se impõe como prioridade para todos os sistemas de ensino. As principais sugestões, neste âmbito são:

1. As instituições de ensino devem providenciar Internet (68\%);

2. Deve parar-se com o ensino-aprendizagem online (18\%).

A primeira é relativa à acessibilidade da Internet. É indiscutível que sem este serviço não se podem desenvolver atividades de ensinoaprendizagem online. É, portanto, um dos requisitos básicos (ANDERSON, 2008a). Entretanto, a questão que se coloca relativamente a esta sugestão é: quem deve providenciar serviços de Internet para viabilizar o processo de aprendizagem online?. Em 
nosso entender, não é justo que se impute esta responsabilidade exclusivamente à instituição de ensino. Também achamos que não é justo que, estando em casa, o estudante não desenvolva atividades de aprendizagem online simplesmente porque a escola não providenciou serviços de Internet.

Efetivamente, achamos que as instituições de ensino funcionam com, para e pela sociedade. Isto justifica a necessidade de um trabalho conjunto entre as instituições escolares e familiares para viabilizar a aprendizagem online, neste caso específico, garantido o acesso à Internet (NHATUVE, 2020). Parece ser muito mais papel (e dever social e moral) dos pais garantir que, estando em casa, numa situação de ensino remoto, o estudante tenha meios para a aprendizagem, do mesmo modo que é seu dever garantir que tenha livros, cadernos, canetas e inclusive casa para morar em situação de aprendizagem tradicional.

A segunda sugestão é consequente dos preconceitos, mundividências e dificuldades dos nossos inquiridos relativamente a esta modalidade nova de ensino-aprendizagem, para a qual não estão devidamente preparados. Entretanto, abdicar desta forma de estudar que, como o dissemos antes, tem vantagens invejáveis quando implementada eficazmente, é negar a mudança e a adaptação necessárias numa sociedade cada vez mais globalizada. É preciso que sejam ultrapassados os preconceitos, sejam criadas as condições de mudança de atitude e seja desenvolvida uma atitude positiva relativamente ao uso das tecnologias e ferramentas digitais, sobretudo no contexto de ensino-aprendizagem (NHATUVE, 2020).

Já no que diz respeito a opiniões e crenças favoráveis a uma aprendizagem online harmoniosa destacam-se posições totalmente apologistas da modalidade online de educação (as instituições devem adotar o ensino-aprendizagem online (9\%); é muito bom e necessário (11\%)), ideias que defendem e encorajam a blended learning que consiste na combinação de estratégias de ensinoaprendizagem online com as de ensino presencial (as instituições devem encorajar o ensino online e o presencial (34\%); é preciso combinar o ensino online e o presencial (27\%).) e aquelas que reconhecem o potencial da aprendizagem online na promoção da independência do aluno na aprendizagem (a aprendizagem online promove o trabalho independente do aluno (8\%)).

As ideias que defendem e encorajam a modalidade online de ensino conformam-se com os princípios teóricos que governam o ensino-aprendizagem online tal como descrito por Anderson (2008a, 200b) e Ally (2008). Na verdade, mais do que nunca, o ensinoaprendizagem online é/deve ser, hoje em dia, encorajado para a promoção da qualidade da educação. Por sua vez, a blended learning (DZIUBAN et al, 2018) é uma modalidade a encorajar, sobretudo em sociedades em desenvolvimento nas quais a modalidade completamente online é nova e é acompanhada de dificuldades acentuadas. Há, entretanto, muitas instituições de ensino que adotaram esta estratégia de ensino-aprendizagem.

Como sugestões favoráveis, ainda que avançadas por um reduzido número de inquiridos, há que reconhecer a sua pertinência para o sucesso da aprendizagem online. Estas sugestões apontam para a necessidade de um trabalho que permita (1) a consciencialização dos estudantes sobre a possibilidade e relevância do ensino-aprendizagem online (2\%) e (2) o uso de plataformas digitais adequadas $(2 \%)$.

A consciencialização dos estudantes e toda a sociedade, tal como temos vindo a defender, é um dos trabalhos preliminares e contínuos para acelerar a mudança e a adaptação perante a nova realidade. Deve ser, sobretudo em países em desenvolvimento, um aspecto a priorizar no design, planeamento e implementação de um projeto de ensino-aprendizagem online (cf. MATTAR; LOUREIRO; RODRIGUES, 2020). A escolha e o uso das plataformas são igualmente deveras importantes. É preciso que as instituições, os professores e também os estudantes superem as suas dificuldades e consigam identificar e usar plataformas, ferramentas e estratégias que, sendo menos onerosas, facilitem a aprendizagem de qualidade (MENDES, et al., 2018; MOREIRA; SCHLEMMER, 2020; MOREIRA; RIGO, 2018; MOREIRA, 2018). 


\section{CONSIDERAÇÕES FINAIS}

Neste estudo, analisámos as opiniões, percepções e sugestões de um grupo de estudantes universitários zimbabweanos e seus pais/encarregados sobre o processo de ensino-aprendizagem online. Os resultados indicam que as percepções dos nossos inquiridos neste âmbito integram dois grupos antagônicos. O primeiro grupo é de ideias adversas (desfavoráveis) e o segundo é de percepções apologistas em relação a modalidade de ensino online.

Entretanto, as primeiras percepções, em termos estatísticos, superam as segundas, i.e., a maioria das opiniões e crenças dos nossos informantes não se conforma com os princípios que governam a aprendizagem online (ANDERSON, 2008a, 2008b; ALLY, 2008); não é a favor nem abonatória a esta modalidade de ensino. Consequentemente, a maior parte das sugestões avançadas pelo nosso grupo alvo revela negação do processo de aprendizagem online.

No entanto, a negação do ensino-aprendizagem online é um posicionamento que pode acarretar consequências avultadas, não só no âmbito das medidas de mitigação dos efeitos negativos da pandemia da Covid-19 na área da educação, mas também, e sobretudo, no âmbito de adaptação às novas formas de viver, de trabalhar, de aprender e de comunicar que, acompanhando os progressos nas áreas da ciência e tecnologia, se impõem nas sociedades (MENESES; FERNANDEZ; REGANA, 2011).

Embora menos representativos em termos estatísticos, identificam-se também ideias e percepções favoráveis a um processo de aprendizagem online harmonioso, podendo destacar-se o reconhecimento da necessidade de adotar o ensino-aprendizagem online, de promovê-lo e de combiná-lo, em certos contextos, com o ensino presencial - blended learning (DZIUBAN et al., 2018).

Nestes moldes, estas opiniões conformam-se com os princípios que governam a aprendizagem online e/ou representam um contributo inovador que abre espaço para a mudança de atitude, a favor da modalidade online de educação. Aliás, as sugestões avançadas neste âmbito sublinham a necessidade de tempo suficiente para a realização de e-atividades, de consciencialização do tecido social sobre a pertinência da aprendizagem online, e de adotar estratégias e escolher ferramentas e plataformas eficazes.

Portanto, conscientes das dificuldades enfrentadas pelos nossos inquiridos, da situação constrangedora causada pela Covid-19, da necessidade de uma atitude positiva face às novas formas de viver, trabalhar, aprender e comunicar que caracterizam a era da ciência e da tecnologia, e reconhecendo as potencialidades (vantagens) da aprendizagem online, achamos que as percepções, os hábitos e a mundividência adversos a este modelo de ensino que prevalecem em algumas sociedades em desenvolvimento devem ser substituídos por atitudes de mudança positiva a favor da nova realidade. Na concepção de projetos de ensino-aprendizagem online devem ser previstas atividades contínuas de consciencialização dos estudantes, dos pais e de toda a sociedade sobre a funcionalidade da educação online.

\section{REFERÊNCIAS}

ALI, W. Online and remote learning in higher education institutes: a necessity in light of Covid-19 pandemic. Higher Education Studies; v. 10, n. 3, p. 16-25, 2020.

ALLY, M. Foundations of educational theory for online learning. In: Anderson, T. (ed.). The theory and practice of online learning. Canada: Au Press, 2008. p. 15-44.

AMANTE, L.; OLIVEIRA, I. Avaliação e feedback. Desafios atuais. Lisboa: Universidade Aberta, 2019.

ANDERSON, T. Towards a theory of online learning. In: ANDERSON, T. (ed.). The theory and practice of online learning. Canada: Au Press, 2008a. p. 45-74. 
ANDERSON, T. Teaching in an Online Learning Context. In: ANDERSON, T. (ed.). The theory and practice of online learning. Canada: Au Press, 2008b. p. 343-366.

BATES, T. Educar na era digital [livro eletrônico]: design, ensino e aprendizagem. São Paulo: Artesanato Educacional, 2017. (Coleção tecnologia educacional 8)

BENTES, J. A. O.; FERREIRA, D. C. N.; SILVA, M. C. Letramentos e afastamento social no contexto da pandemia: o que pensam os discentes do ensino médio de escolas públicas de Belém-Pa? Revista INTERACÇÕES, n. 55, p. 227-249, 2020. Disponível em: file://C:/Users/Life/Downloads/20718-Texto\%20do\%20Trabalho-85529-1-10-20201230.pdf. Acesso: 1 jan. 2021.

DEMUYAKOR, J. Coronavirus (Covid-19) and online learning in higher institutions of education: A survey of the perceptions of ghananian international students in China. Online Journal of Communication and Media Technologies, v.10 n. 3, p. 1-9, 2020.

DZIUBAN, C; GRAHAM, C.; MOSKAL, P.; NORBERG, A.; SICILIA, N. Blended learning: the new normal and emerging technologies. International Journal of Educational Technology in Higher Education, v. 15 n. 3, p. 1-16, 2018. Disponível em: https://doi.org/10.1186/s41239-017-0087-5. Acesso: 30 set.2020.

IMPACTO DA COVID-19 EM ÁFRICA. 2020. Disponível em: https://www.unicef. org/angola/media/2431/file/Resumo\%20da\%20Pol\%C3\%ADtica:\%20Impacto\%20da\%20COVID19\%20nas\%20crian\%C3\%A7as. pdf. Acesso: 30 set. 2020.

MATTAR, J.; LOUREIRO, A.; RODRIGUES, E. Educação online em tempos de pandemia - desafios e oportunidades para professores e alunos. Revista INTERACÇÕES, n. 55, p. 1-5, 2020. Disponível em: https://doi.org/10.25755/int.22001. Acesso: 1 jan. 2021.

MEANS, B.; BAKIA, M.; MURPHY, R. Learning online: what research tells us about whether, When and how. New York: Routledge Taylor \& Frances, 2014.

MENDES, A. Q. et al. Modelo pedagógico virtual: Cenários de desenvolvimento. Lisboa: Universidade Aberta, 2018.

MENESES, E. L.; FERNANDEZ, G. D.; REGANA, C. B. E-Actividades: elementos constitutivos para la calidad de la praxis educativa digital. In: ROIG V. R.; LANEVE, C. (ed..). La práctica educativa en la sociedad de la información. Innovación através de la investigación. Alcoy - Brescia: Marfil \& La Scuola Editrice, 2011.p. 267-281.

MOREIRA, A. Reconfigurando ecossistemas digitais de aprendizagem com tecnologias audiovisuais. Em Rede: Revista de Educação à Distância, v. 5, n. 1, p. 5-15, 2018. Disponível em: https://www.aunirede.org.br/revista/index.php/emrede/article/view/305. Acesso: 30 set. 2020.

MOREIRA, J. A, M; RIGO, R. M. Definindo ecossistemas de aprendizagem em rede: Percepções de professores envolvidos em processos de formação. Debates em Educação, v. 10, n. 22, 2018, p. 107-120. Disponível em: https://doi.org/10.28998/21756600.2018v10n22p107-120. Acesso: 30 set. 2020.

MOREIRA, J. A; SCHLEMMER, E. Por um novo conceito e paradigma de educação digital onlife. Revista UFG, v.20, p. 2-35, 2020. Disponível em: https://doi.org/10.5216/revufg.v20.63438. Acesso: 30 mar. 2021. 
NHATUVE, D. Ensino-aprendizagem online em países em desenvolvimento: o papel do aluno. Revista INTERACÇÕES, n. 55, p. 207-226, 2020. Disponível em: https://doi.org/10.25755/int.21084. Acesso: 1 jan. 2021.

SANTOS, J.; R. E ZABOROSKI, E. A. Ensino remoto e pandemia covid-19: desafios e oportunidades de alunos e professores. Revista INTERACÇÕES, n. 55, p. 41-57, 2020. Disponível em: https://doi.org/10.25755/int.20865. Acesso: 1 jan. 2021.

\section{(1) $\circledast \circledast$}

Recebido em 25/02/2021. Aceito em 11/08/2021. 